\title{
Complutum
}

ISSN: 1131-6993

\section{La estela de guerrero y la estela antropomorfa de Pedra Alta (Castrelo de Val, Galicia $)^{1}$}

\author{
Manuel Santos-Estévez ${ }^{2}$; Patricia Mañana-Borrazás ${ }^{3}$; Nieves Amado Rolán ${ }^{4}$; Hugo Pires ${ }^{5}$
}

Recibido: 16 de diciembre de 2016 / Aceptado: 3 de agosto de 2017

Resumen. El propósito de este artículo es describir una estela descubierta en el municipio de Castrelo do Val (Ourense) y realizar un primer análisis sobre su iconografía, estilo y cronología. Esta estela presenta una serie de grabados muy semejantes a los de las estelas de guerrero del sudoeste y unas de escotaduras que confieren a la piedra un aspecto vagamente antropomorfo. Se propone la existencia de tres posibles momentos sucesivos de uso para este monumento; el más antiguo con grabados rupestres atlánticos, el segundo con una iconografía propia de las Estelas de Guerrero y un tercero en el que se realizan las escotaduras.

Palabras clave: estela antropomorfa; estela de guerrero; Edad del Bronce; grabados rupestres.

\section{[en] The Warrior Stelae and the Anthropomorph Stele of Pedra Alta (Castrelo do Val, Galicia)}

Abstract. The aim of this article is to describe a stela discovered in the municipality of Castrelo do Val (Ourense) and realises a first analysis on its iconography, style and chronology. This stele presents a series of carvings with very similar to those found in warrior stelae of the southwest of Iberia, and a series of recesses that confer to the stone an antropomorphic appearance. The paper proposes the existence of three possible subsequent moments of use for this monument; the oldest one with Atlantic rock art, the second one with a warrior stele iconography and the third one when the recesses were made.

Keywords: Antropomorph Stela; Warrior Stela; Bronze Age; Rock Engravings.

Sumario. 1. Circunstancias del hallazgo. 2. Contexto geográfico y arqueológico. 3. Descripción tecno-morfológica de Pedra Alta. 4. Diseños grabados. 5. Lectura de los grabados. 6. Tipología y adscripción cronológica. 7. Conclusiones.

Cómo citar: Santos-Estévez, M. et al. (2017): La estela de guerrero y la estela antropomorfa de Pedra Alta (Castrelo de Val, Galicia). Complutum, 28(1): 71-86.

Pretendemos con este artículo realizar una descripción detallada de una estela descubierta en 2010 en la provincia de Ourense. Desde su pu- blicación en la prensa, la estela conocida como Pedra Alta, fue identificada como una estela de guerrero datable en el Bronce Final. Un análisis

\footnotetext{
Este trabajo tiene el apoyo financiero del projecto Lab2.pt-Laboratório de Paisagens, Património e Território-AUR104509 y de la FCT del Ministério de Educação e Ciência de Portugal a través del proyecto: "Paisagem e representação do poder na Pré-história Recente: Arte Atlântica e Estátuas-Menir" (PARES) con código: SFRH/BPD/93700/2013.

2 Laboratório das Paisagens, Património e Território - Lab2PT. Universidade do Minho, Braga (Portugal)

E-mail:manuel.santos@mundo-r.com

3 Instituto de Ciencias del Patrimonio (Incipit). Consejo Superior de Investigaciones Científicas (CSIC) (España) E-mail: patricia.manana-borrazas@incipit.csic.es

4 Arqueóloga profesional

E-mail: nieves.amado@gmail.com

5 Centro de Estudos de Arquitectura e Urbanismo, Faculdade de Arquitectura da Universidade do Porto (Portugal)

E-mail: hpires@arq.up.pt
} 
más pormenorizado nos permite plantear que esta pieza arqueológica fue objeto de diversas transformaciones, desde un posible origen como petroglifo neolítico, con posterioridad fue decorada con diseños típicos de las estelas de guerrero del sudoeste ibérico para; finalmente, ser convertida en una estela antropomorfa.

\section{Circunstancias del hallazgo}

Todavía algunos vecinos del lugar aseguran haber visto la estela formando parte de una cerca en una antigua finca, por ello juzgamos como muy probable que esta piedra pudiera haber sido sepultada durante los trabajos de concentración parcelaria llevados a cabo en los años 70 del siglo XX. El caso es que la pieza fue desenterrada, de forma casual, arando con un tractor en el otoño de 2009 en el término municipal de Castrelo do Val (Ourense), en un paraje conocido como Pedra Alta, en la margen izquierda del río Támega, en una zona de vadeo de este mismo río y cercana al límite con el ayuntamiento de Verín (Fig. 1). La pieza quedó parcialmente destapada hasta el año siguiente en el que un vecino, Xosé Lois Lozano Rúa, observó unos grabados en la superficie de la piedra, es en este momento cuando se da a conocer el hallazgo con un notable impacto en la prensa gallega. La primera lectura de los grabados es realizada por Peña Santos, Alberte Reboreda y Breogán Nieto quienes identifican la piedra como una estela de guerrero y así será publicada por Aparicio Casado et al. (2013: 81). Desde entonces, se han sucedido diversas disputas en relación al depósito de la pieza arqueológica, así como desencuentros entre su descubridor y las diferentes administraciones autonómica y municipal. En la actualidad, la piedra se halla depositada en el Museo Provincial de Ourense ${ }^{6}$. Como veremos, esta pieza ha experimentado transformaciones diversas en diferentes periodos históricos y es posible que estos cambios afectasen también a su emplazamiento, aunque nos inclinamos por pensar que la localización original no debió encontrarse demasiado distante del lugar del hallazgo. Debemos tener en cuenta las dificultades que en principio podría ofrecer para su desplazamiento una piedra con un peso aproximado de 800 kg., según el informe del Museo de Ourense, pero sobre todo, hay que hacer notar los paralelismos entre el lugar del hallazgo y el patrón de emplazamiento de las estelas del sudoeste con las que esta pieza guarda estrechas semejanzas. El lugar del hallazgo se sitúa en las siguientes coordenadas UTM: X: 629.697, Y: 4.648.667. Altitud 403 m.s.n.m.

\section{Contexto geográfico y arqueológico}

La estela fue encontrada en el fondo del valle en el Alto del Támega. Este valle presenta una forma topográfica llana y hundida, rodeada por relieves montañosos con altitudes de $1.025 \mathrm{y}$ 1.595 m.s.n.m. que la circundan dejando una abertura hacia el sur en su camino hacia el Duero (Fig. 2). La apertura del Alto Támega hacia Portugal por un valle con un tránsito fácil, y la cercanía a la Submeseta Norte, lo convierten en un importante nudo de comunicaciones y paso obligado desde el sur de Galicia hacia el norte y desde la costa hacia la meseta y el resto de la Península.

La depresión tectónica está atravesada por una falla por las que fluyen numerosas surgencias de aguas minero-medicinales. La litología de la comarca está conformada mayoritariamente por esquistos, cuarcitas y pizarras excepto en el suroeste que es de granito, que aparece en forma de filones en ambas márgenes de la cuenca. Debemos señalar pues, que en el entorno del lugar del hallazgo de la estela no se encuentran afloramientos graníticos, material en el que está hecha la estela, hasta recorridos varios kilómetros hacia el oeste. El fondo del valle está formado por sedimentos cuaternarios. Las sierras que limitan el valle contienen grandes mineralizaciones de estaño, siendo una de las zonas mas ricas de la península, tanto en cantidad como en calidad. Son históricas las minas de la Serra de Meda (Arcucelos, Souteliño) y las de Vilardecervos, ambas explotadas por la Corona de Castilla desde el siglo XVIII. También hay algo de hierro y oro, éste explotado ya en época romana en minas primarias y secundarias.

No hay evidencias en superficie de restos arqueológicos en las inmediaciones de la estela. Pero sí existe un contexto arqueológico muy rico y diverso, en el entorno y en toda la cuenca del Alto Támega ${ }^{7}$. En un radio aproximado de $1 \mathrm{~km}$. se sitúa el Castro da Cabanca, de la Edad del Hierro, los asentamientos romanos de Os Castros, Os Coios, Nocedo do Val, Vilamaior, Pepín y Gondulfes. También se documenta la necrópolis romano-medieval de San Martiño. Otro elemento significativo del 

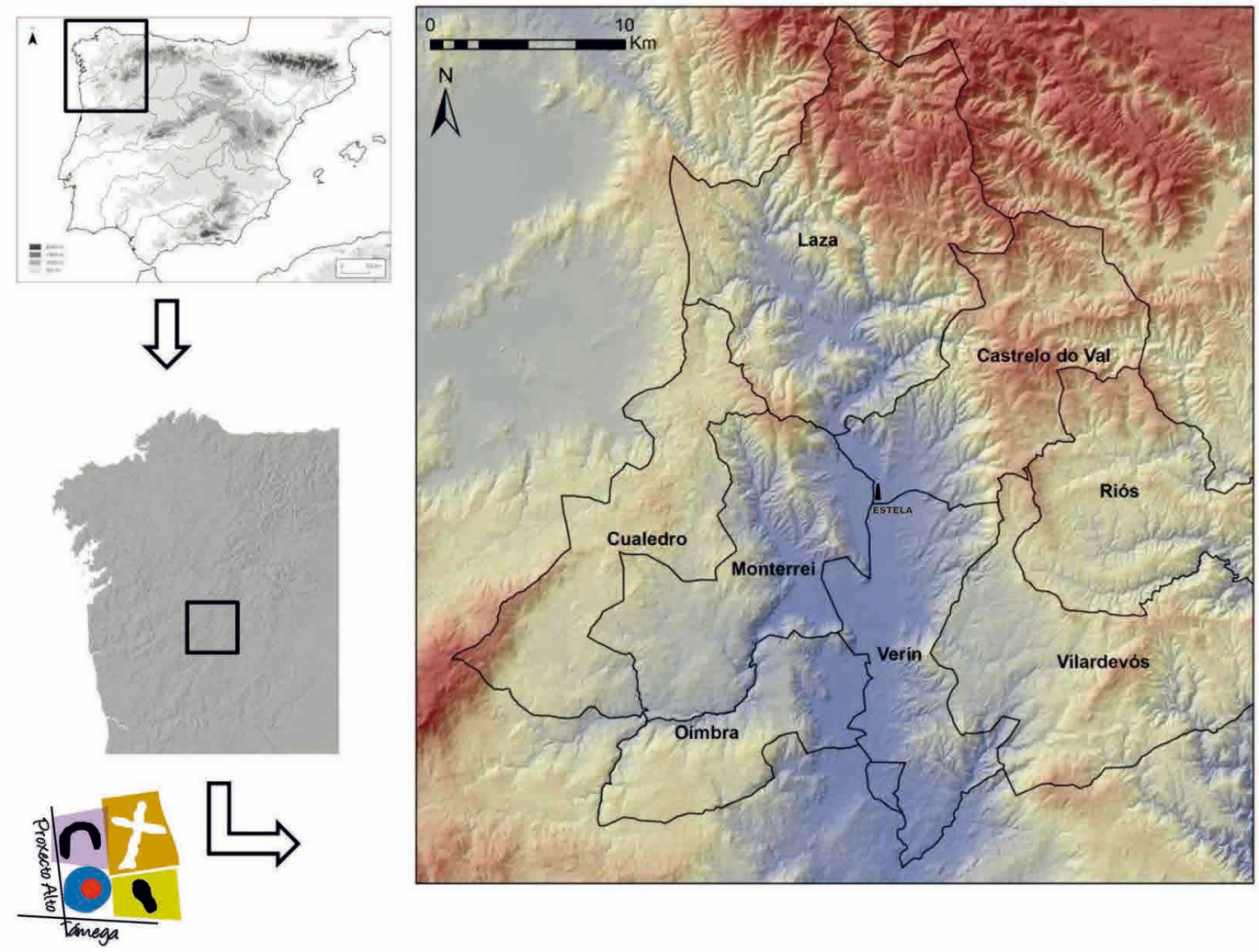

Figura 1. Localización de la estela de Castrelo do Val en la Península Ibérica.

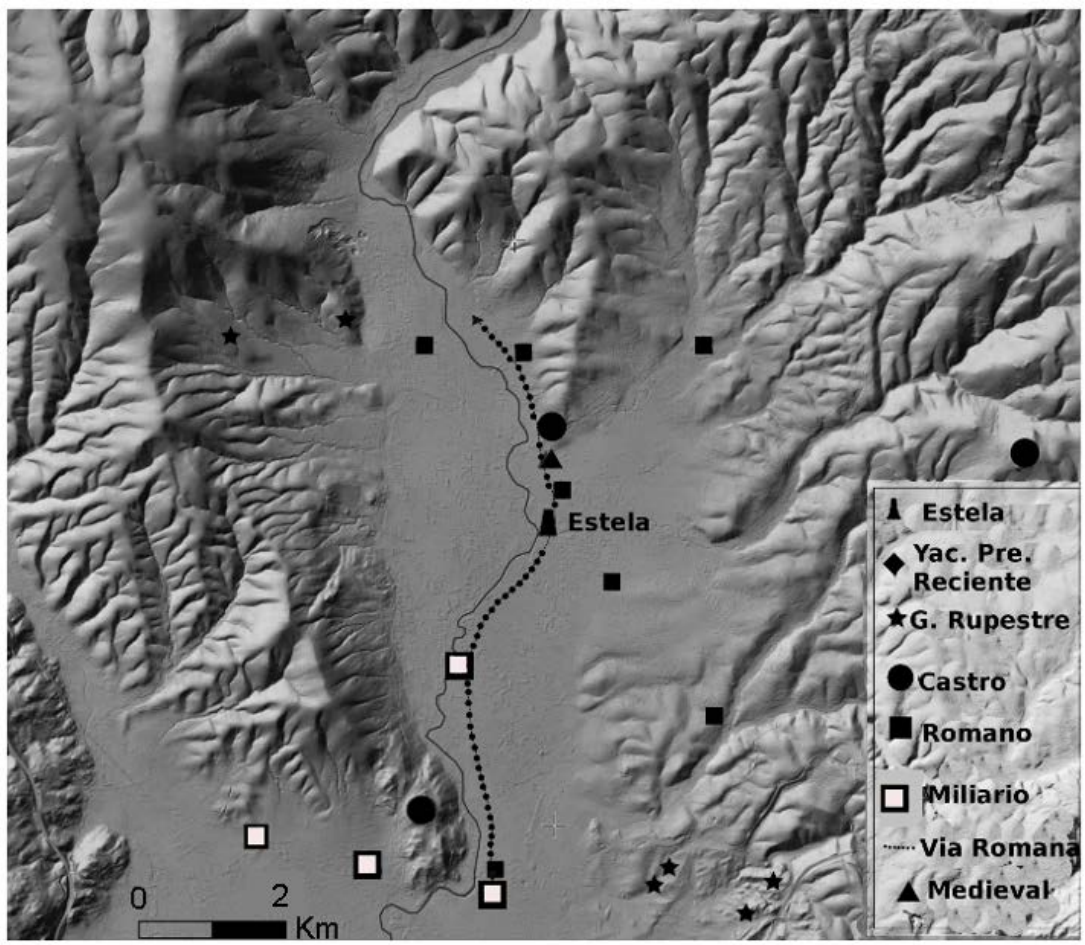

Figura 2. Localización y contexto arqueológico de la estela en el Alto Támega. 


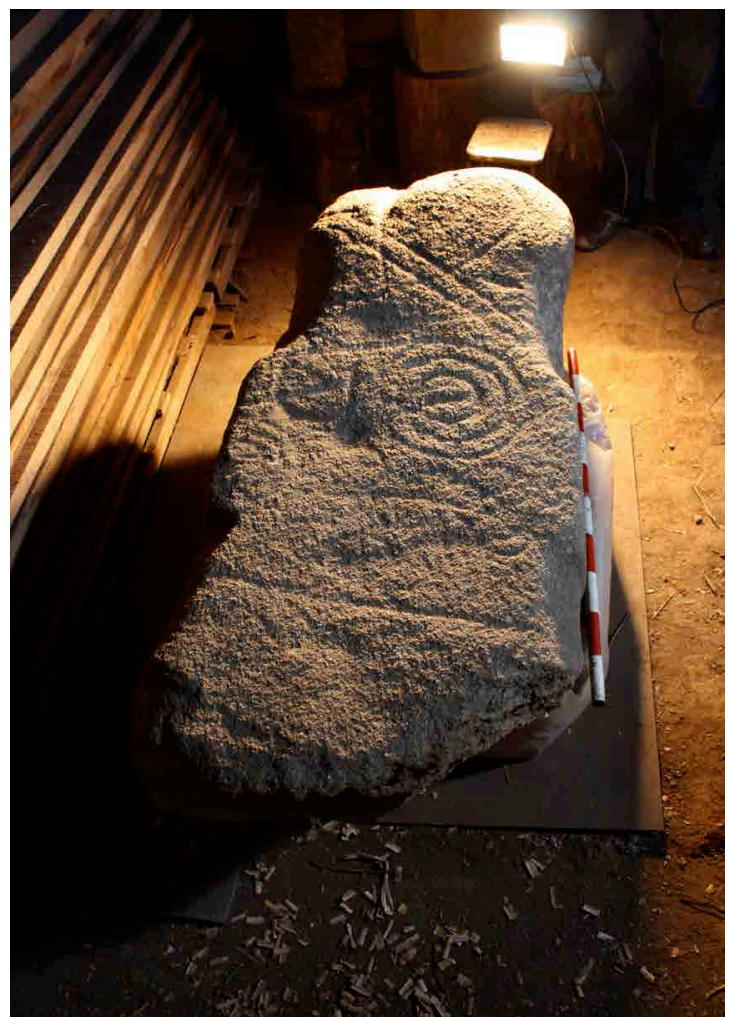

Figura 3. Vista general de Pedra Alta con luz rasante.

entorno pudo haber sido la vía romana secundaria que unía Chaves con Lugo a través de los valles del Támega, Arnoia y Miño, conocida como "Vía romana del Támega" y que discurriría muy cerca de Pedra Alta.

Si ampliamos la distancia, el registro arqueológico prehistórico es más abundante. En toda la comarca del Támega encontramos unos 30 túmulos, mayoritariamente datables en el Neolítico, así como asentamientos domésticos desde el Neolítico (Alto da Plaza) hasta la Edad del Bronce (Campos do Sapo) pasando por el Calcolítico (Castelo das Chas, Os Bacelos, Baixada de San Xosé, A Míllara). También han sido documentados yacimientos funerarios de la Edad del Bronce, más de 100 petroglifos y algunos notables ejemplos de estatuaria prehistórica.

\section{Descripción tecno-morfológica de Pedra Alta}

Se trata de una estela de granito con forma aproximadamente antropomorfa y con grabados en ambas caras, aunque los diseños más numerosos y complejos se localizan solamente en una de ellas. En la actualidad las medidas son 1,64 metros de longitud por 0,70 metros de ancho y 0,31 de grosor. La piedra no parece estar completa, ya que en la parte inferior se aprecian evidencias de una ruptura, por lo que su longitud debió ser mayor; calculamos que su altura original debió superar los 2 metros si consideramos que la estela debió estar hincada en el suelo con la totalidad de sus grabados visibles. El perfil general de la piedra es la de un rectángulo con cuatro escotaduras, dos en cada uno de los lados largos, la parte superior presenta un remate vagamente semicircular.

Precisamente son las cuatro escotaduras las que le confieren a la piedra cierto aspecto antropomorfo, característica también presente en estatuas menhir geográficamente próximas como A Ermida (Ponte da Barca) o la de Faiões (Chaves) ambas en Portugal, situada ésta en el mismo valle que Pedra Alta. Los dos rebajes superiores podrían estar definiendo la cabeza, la parte media, situada entre las cuatro escotaduras representaría el tronco y, la parte inferior podría corresponderse con las piernas. Respecto a la ejecución de las escotaduras, se observa una peculiaridad de no fácil interpretación; la escotadura superior izquierda llega a invadir la cara posterior de la estela, algo que no ocurre con las otras tres, esto podría indicar que, una primera intención de los artesanos fue la de rodear las dos caras con el rebaje, labor que no se llegó a terminar. Quizás el propósito inicial fuese el de construir una figura observable por las dos caras, idea que sería abandonada, de este modo, el perfil antropomorfo es solo visible frontalmente. En este sentido, hay que hacer notar la tosquedad de la superficie del reverso de la pieza frente a una superficie anversa más uniforme y lisa.

La piedra no presenta un estado de conservación óptimo. Ya hemos mencionado la pérdida de la parte inferior, que presumiblemente no tendría grabados, ya que sería ésta la parte enterrada que posibilitaría la posición vertical de la estela, aunque este extremo no se puede afirmar con seguridad. La superficie presenta diversos surcos producidos, posiblemente, por el paso de arados. También debieron repercutir negativamente en su conservación las obras de concentración parcelaria, que implicarían la circulación de maquinaria pesada, la apertura de caminos, remociones de tierras, etc. El desgaste de la superficie es especialmente intensa en el tercio inferior de la piedra. 


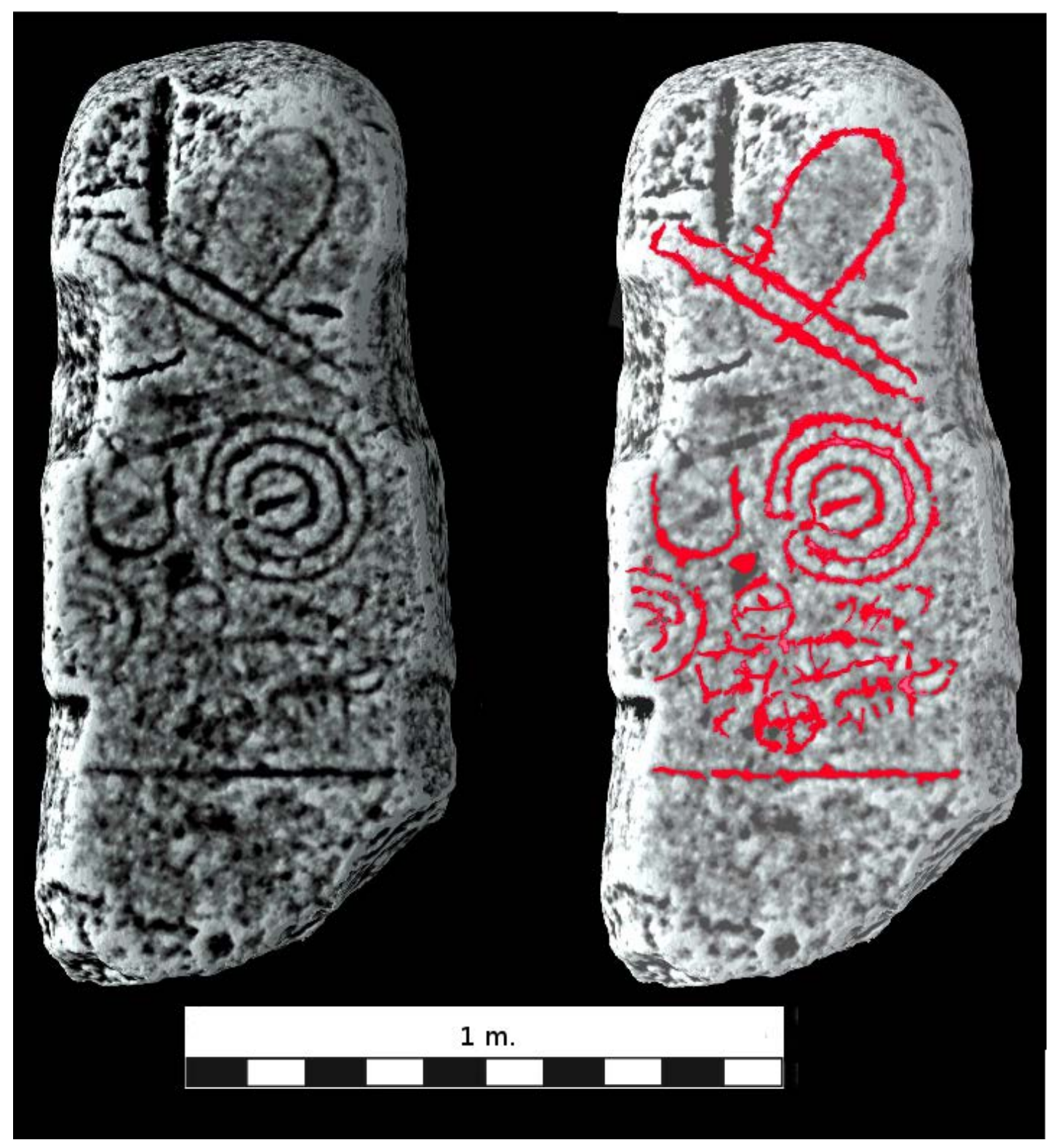

Figura 4. Modelo digital de superficie de Pedra Alta obtenido por fotogrametría y resultado de la aplicación del MRM donde se evidencian los grabados.

La superficie de la estela presenta cierto grado de abrasión, muy posiblemente intencional. Dicha abrasión se observa de forma más ligera en la cara principal y con mucha más claridad en los laterales de la piedra. Este aspecto no se detecta en la cara posterior. La abrasión de la cara principal es observable sobre todo en los granos de cuarzo, que presentan estrías de desgaste unidireccional, las cuales fueron realizadas desde la parte inferior de la estela hacia la superior. Teniendo en cuenta la orientación de las mencionadas microestrías, es muy posible que este leve pulido fuese producido durante un traslado de la piedra mediante arrastre, con lo que se conseguiría una doble finalidad con el mismo trabajo: trasladar la piedra y uniformizar la superficie. Por otro lado, debemos señalar que es en los bordes, y especialmente en las cuatro escotaduras, donde el pulido es más intenso y sin duda intencional.

\section{Diseños grabados}

Para un registro fiable de los grabados conviene el empleo de diferentes sistemas de ob- 


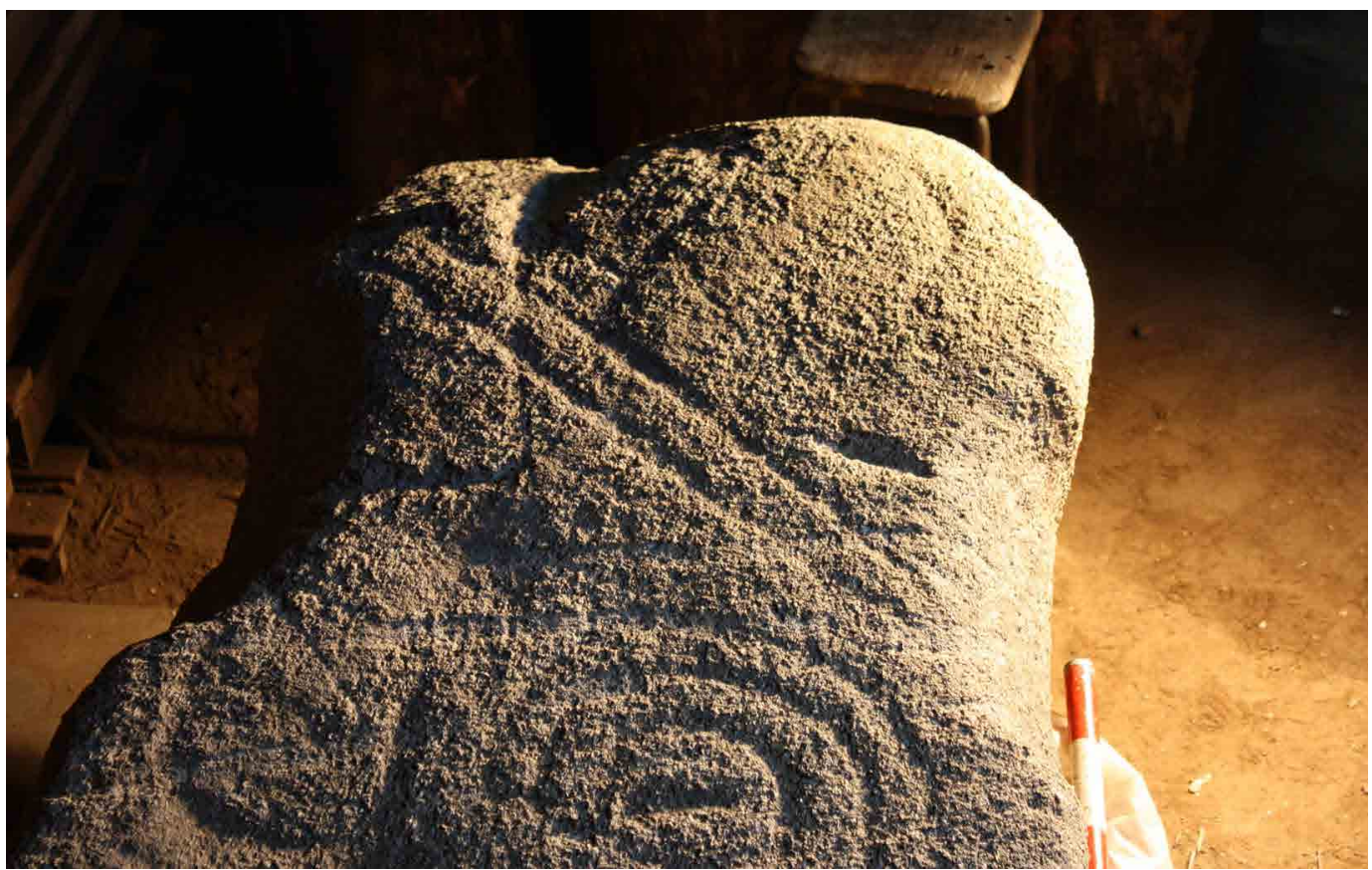

Figura 5. Tercio superior de la estela donde se observa la figura oval incompleta y la espada.

servación. Cada técnica usada puede revelar aspectos distintos de la decoración. Por esta razón, para una adecuada lectura y registro de las insculturas, han sido empleadas diferentes técnicas que han aportado información complementaria y coherente. Dichas técnicas han sido las siguientes:

1. Observación de los grabados con luz natural. En el momento de la lectura, la estela se encontraba en un lugar cerrado e iluminado por la luz baja y lateral de la puerta de acceso. Dichas condiciones son bastante apropiadas para la observación de grabados.

2. Iluminación de los grabados mediante luz artificial con diversas orientaciones.

3. Observación de los grabados humedeciendo la superficie.

4. Frotagge con papel carbón sobre hoja de papel blanco y posterior tratamiento digital.

5. Observación y tratamiento digital de las fotografías realizadas bajo diferentes condiciones de visibilidad.

6. Registro fotogramétrico de la pieza.

7. Análisis micro-morfológica de la superficie pétrea.

La combinación de las diferentes técnicas ha permitido una lectura muy detallada de los diseños grabados. Las 5 primeras técnicas de la lista son conocidas por los especialistas en arte rupestre grabado (Seoane Veiga 2009). El registro fotogramétrico de la pieza se ha hecho mediante una colección de 79 fotografías perpendiculares a la superficie grabada obtenidas con una cámara réflex Nikon D300, 3216×2136 píxeles de resolución a una distancia media de 1, $20 \mathrm{~m}$. y procesadas mediante Agisoft PhotoScan pro, un programa de fotogrametría que aplica la técnica de Structure from Motion, lo que ha permitido generar un modelo 3D de detalle ${ }^{8}$. Los metadatos del proceso de modelado 3D son los siguientes:

$\mathrm{N}^{\mathrm{o}}$ Puntos nube dispersa: 174.449 puntos de un total de 322.099, tras proceso de filtrado, eliminación de residuo y de superficie que no correspondía a la superficie de la estela.

Error de reproyección: 0.299 píxeles

Proyecciones: 684.339

$\mathrm{N}^{\mathrm{o}}$ puntos nube de puntos densa: 6.191 .668 puntos

Modelo 3D: 7.613 .865 caras

Resolución del Modelo Digital de Superficie (DEM): $0.817 \mathrm{~mm} / \mathrm{pix}$

Densidad de puntos del Modelo Digital de Superficie (DEM): 1.5 puntos/mm2

Para el análisis digital de la superficie 3D se ha aplicado el algoritmo Modelo de Residuo Morfológico (MRM) desarrollado por uno de los autores (João Caninas et al 2011; Hugo Pires et al. 2014), que permite detectar y visualizar microformas de modelos digitales de 
superficie y así, resaltar los rebajes y/o grabados. El micro-relieve queda así representado por una gama de tonos o colores contrastantes, eliminando de la visualización los fenómenos ópticos provocados por la iluminación rasante. Con esta técnica se ha obtenido una representación detallada y objetiva de las características micro-morfológicas de la estela, permitiendo así superar la dificultad de percepción y eliminar la subjetividad del registro gráfico.

\section{Lectura de los grabados}

Las dificultades que hemos encontrado a la hora de identificar los diseños representados en la estela son de dos tipos. Por un lado, no todas las figuras parecen haber sido realizadas en un mismo episodio, algunas parecen haber sido modificadas, otras parcialmente borradas, en otras palabras, la iconografía de la estela debió experimentar sucesivas modificaciones. Por otro lado, es corriente que, en arte prehistórico, como son las estelas de guerrero, las figuras no representen de forma fiel los objetos a los que hacen referencia, sino que suelen ser representaciones convencionales con cierto grado de esquematismo. En todo caso, en Pedra Alta han sido definidos un total de 9 grabados en la superficie de la estela (Fig. 4). A continuación procedemos su descripción:

Grabado 1. Situado en la parte más elevada, se trata de un óvalo incompleto unido a una segunda figura que representa una espada. Precisamente por su relación con la espada, una de las posibles interpretaciones es la de una correa de sujeción, al no estar la supuesta correa rodeando la piedra, se podría deducir que la intención del grabador fue la de representar este artefacto como depositado y no puesto en la cintura u hombro de su portador.

Otra posible interpretación viene sugerida por la comparación con las estelas de guerrero del sudoeste. Tanto por su posición, en la parte más alta de la composición, como por su forma, podríamos considerar como probable que esta figura ovalada represente un casco. A este respecto debemos señalar la presencia de al menos dos apéndices en el lado izquierdo que recuerdan a los observados en cascos grabados en las estelas de guerrero de Cáceres, concretamente a las de Santa Ana de Trujillo, Valencia de Alcántara y Zarza de Montánchez. Contra esta interpretación debemos señalar que el perfil de la figura no es triangular como en el caso de las estelas extremeñas, sino que se trata de un óvalo abierto que se estrecha en la parte inferior.

Una tercera posibilidad es que se trate de un grabado sin relación directa con el conjunto y que fuese realizado en un momento anterior a la espada. A favor de esta posibilidad, tenemos el hecho de que el surco del óvalo continúa a través de la espada, tal y como se puede ver en el levantamiento fotogramétrico. Asimismo, podemos observar como el surco es menos profundo en el segmento comprendido dentro del perfil de la espada, lo que parece indicar que la hoja de la espada se realizó con posterioridad al óvalo.

Grabado 2. Se trata de una espada casi completa situada inmediatamente debajo de la figura anterior. No resulta fácil definir el modelo concreto de espada. Es muy posible que esté representada a tamaño natural, el diseño tiene $54 \mathrm{~cm}$. de longitud. Se ha perdido parte de la punta por un pequeño desconchado y por el corte producido por la escotadura superior derecha (Fig. 5). La empuñadura presenta un remate redondeado y, aparentemente una guarda en V abierta. Respecto a la hoja, no podemos observar un perfil pistiliforme, más bien la espada presenta dos filos paralelos que se tornan convergentes en el extremo distal. En definitiva, la forma de la misma, en términos generales, parece tratarse de una espada del Bronce Final, especialmente si atendemos a la forma de la guarda. Debemos destacar la posición poco corriente en el conjunto de la composición si la comparamos con las estelas del sudoeste, ya que, en la práctica totalidad de los casos, la espada se sitúa en una posición inferior al escudo, mientras que en Pedra Alta se sitúa en una posición superior.

Grabado 3. Figura formada por 3 círculos concéntricos, situada bajo la figura de la espada (Fig. 6). Muy posiblemente se trate de la representación de un escudo del Bronce Final, identificable por la presencia de una escotadura que atraviesa los círculos concéntricos de la decoración del mismo. Esta escotadura parece presentar una forma en $\mathrm{V}$, forma característica de este elemento en los escudos de las estelas de guerrero y de sus correlatos hechos en cuero o metal que se distribuyen por Europa Occidental y la Europa Mediterránea. Respecto a este diseño, destacamos que los círculos son muy regulares, al contrario de lo que sucede en la gran mayoría de los casos de las estelas del suroeste. Tampoco aparecen representados 


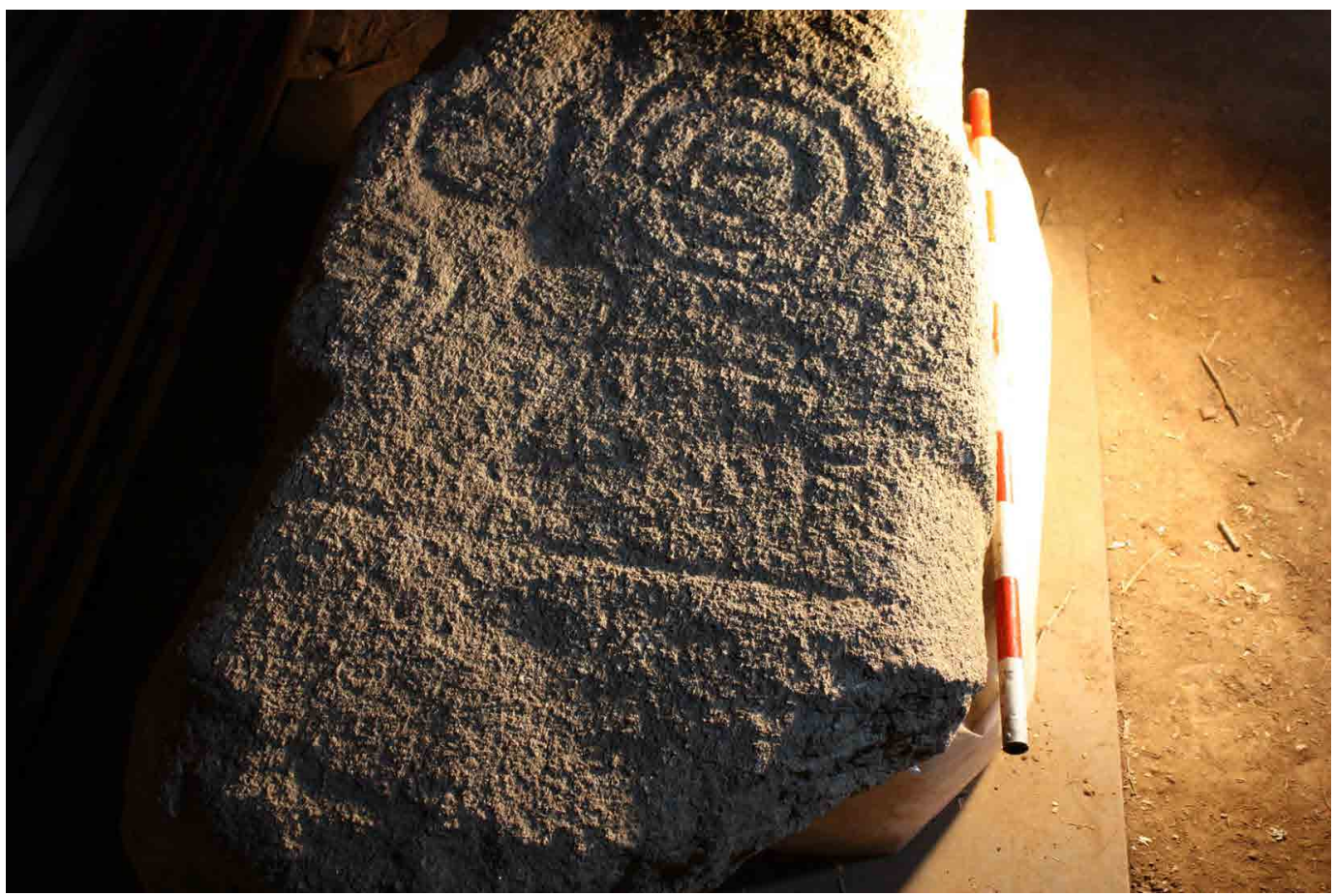

Figura 6. Parte central e inferior de la estela donde se observa el escudo, los círculos concéntricos cortados, la posible lira, el carro y la posible lanza.

los remaches. Finalmente, el escudo presenta una abrazadera en la parte central figurada por una línea recta, lo que nos indica que esta arma fue representada por el reverso, es decir, que no estaría siendo asida, sino que estaría depositada, tal y como sucede en las estelas del sudoeste. También debemos mencionar que la forma de esta figura recuerda en buena medida a las combinaciones circulares características del arte rupestre Atlántico.

Grabado 4. Figura situada a la izquierda del escudo (Fig. 6). Presenta una forma en U con las líneas verticales rectas y paralelas y la horizontal ligeramente arqueada. No es una figura de fácil interpretación pero, siguiendo la iconografía de las restantes estelas de guerreros podría considerarse una posible representación de una lira, aunque en todo caso se trataría de una representación muy esquemática.

Grabado 5. Cazoleta de forma irregular situada bajo la figura anterior (Fig. 6). No se observa una relación iconográfica clara con el conjunto de los grabados. Pudiera no tener relación con el diseño final de la pieza, por lo que no habría que descartar que se tratase de un elemento relacionado con una composición anterior.
Grabado 6. Se trata de una figura que interpretamos como un carro, se sitúa bajo el escudo anteriormente descrito (Figs. 6 y 7). A pesar de las dificultades que ofrece la lectura de esta figura, debido al alto grado de erosión, podemos señalar que parece tratarse de un carro de dos ruedas de cuatro radios. La indicación de los cuatro radios es minoritaria en las estelas del suroeste ibérico, las observamos en Cabeza del Buey I (Badajoz) o Ategua (Córdoba). Generalmente, en las estelas de guerrero, este detalle aparece como un círculo simple de pequeño tamaño o con un punto central, en otros casos se representan ruedas macizas. Debido al mal estado de conservación, no es posible decir mucho acerca de los detalles del carro. Una serie de líneas cortas, paralelas y verticales situadas a la derecha de la rueda inferior parecen representar a los animales de tiro. (Fig. 7). Casi cualquier afirmación sobre la forma del carro debe ser tomada con cierta precaución, en cualquier caso, podría tratarse de un carro ligero con un eje desplazado a la parte trasera de la caja con ruedas de cuatro radios y tirado por dos caballos o quizás por bóvidos. La forma de la caja parece ser más alargada que las que aparecen con más frecuencia en las estelas 

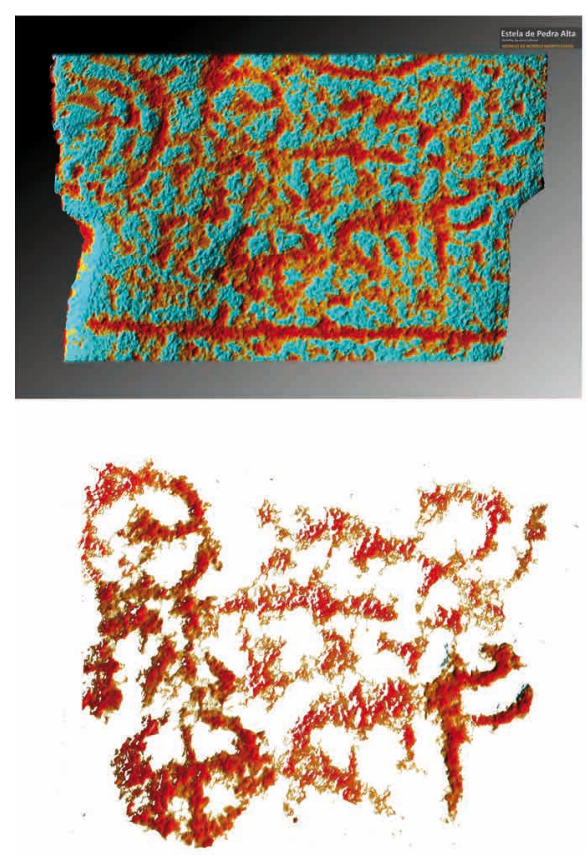

Figura 7. Fotogrametría del posible carro y resalte de los surcos del grabado.

de guerrero, en cierto modo su forma podría aproximarse a los carros documentados en los grabados rupestres de la Roca de los Carros en Badajoz y otras representaciones existentes en Extremadura (Collado Giraldo 2015).

Grabado 7. Figura formada por tres círculos concéntricos incompletos situados a la izquierda del carro (Fig. 6). Su diseño, al igual que el escudo, guarda evidentes semejanzas con los motivos circulares del arte rupestre Atlántico. Los surcos están más erosionados que los del escudo y la separación entre los anillos es ligeramente menor. Esta figura fue cortada, posiblemente cuando se llevó a cabo la extracción de la piedra, también se vio afectada por el pulido de los laterales de la misma. Por esto último, pensamos que esta figura no parece formar parte de la composición general de la estela. Esta hipótesis abre la posibilidad de que este grabado estuviese relacionado con un uso anterior de este mismo monumento. La presencia de este motivo cortado, podría indicar que la piedra formó parte de un grabado rupestre en un afloramiento natural posteriormente extraído para la construcción de la estela. Esta posibilidad podría explicar en parte la mayor irregularidad del reverso de la estela, que al corresponderse con la parte unida a la roca natural, estaría menos erosionada.

Grabado 8. Línea horizontal situada en la parte inferior de la estela (Fig. 6). Podría tra- tarse de un cinturón o bien de una lanza. La lanza es uno de los elementos más característicos de las estelas de guerrero, aunque no podemos asegurar que se trate de este tipo de arma, debido a que fueron cortados ambos extremos cuando se realizaron las escotaduras inferiores. En el caso de ser una lanza, habría que señalar que su posición difiere de las estelas del sudoeste, donde la lanza aparece en una posición superior a la del escudo, aunque también es importante tener en cuenta que la lanza, junto con el escudo y la espada, es uno de los tres elementos presentes en toda estela de guerrero, por lo que su ausencia en Pedra Alta no sería fácil de explicar.

Grabado 9. La cara posterior de la estela, concretamente en su parte inferior, presenta tres cazoletas (Fig. 8). Es difícil definir la relación de estas cazoletas con el conjunto del monumento. Tampoco podemos descartar la posibilidad de que estuvieran relacionadas con un antiguo uso de la pieza o incluso con un uso más reciente.

\section{Tipología y adscripción cronológica}

Para Comendador y González ${ }^{9}$ Pedra Alta sería un modelo sincrético entre estatuas menhir, propias de la zona donde fue localizada y las estelas del sudoeste. Terroba Souto (2015: 


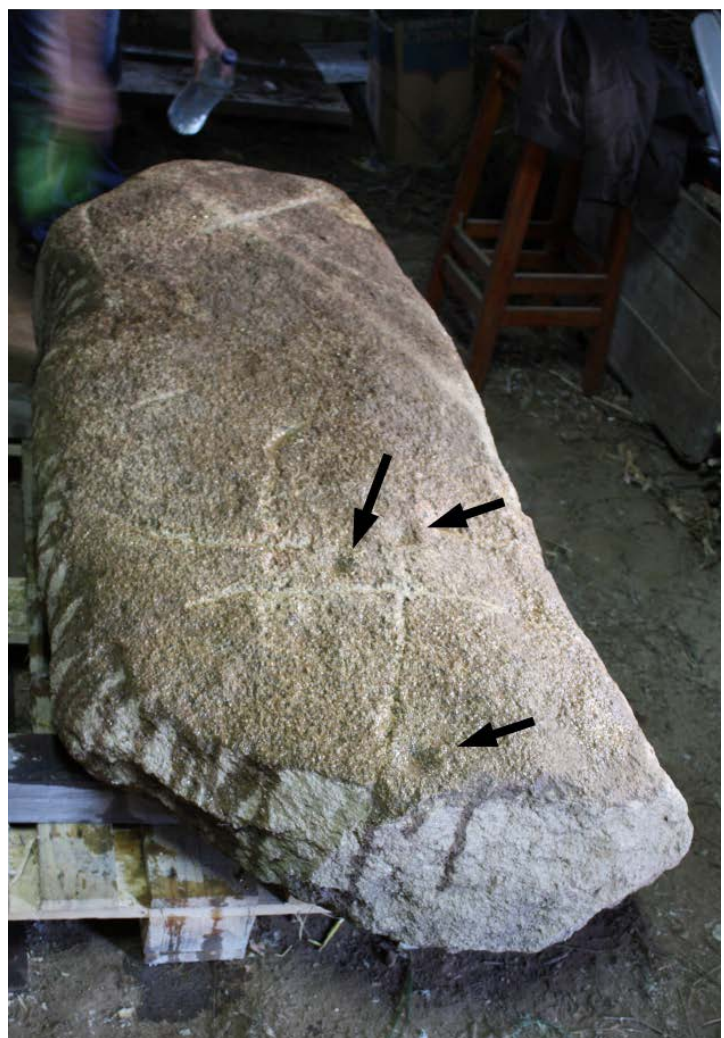

Figura 8. Cara posterior donde se observan las tres cazoletas.

13) plantea la existencia de dos fases para la producción de la estela de Castrelo do Val, un primer momento en el que se observan características formales que recuerdan a las denominadas estatuas menhir del noroeste Ibérico, $\mathrm{y}$ un segundo momento en el que se introduce una iconografía típica de las estelas de guerrero del sudoeste. Efectivamente, estamos ante una pieza de cierta complejidad debido a las diversas transformaciones experimentadas a lo largo del tiempo. Los rebajes laterales son quizás los elementos que parecen conectar Pedra Alta con algunas estatuas menhir del noroeste ibérico. El perfil aproximadamente antropomorfo se observa en otras piezas localizadas en zonas próximas, como por ejemplo las de Ermida (Ponte da Barca), Faiões (Chaves), Marco (Vila Pouça de Aguiar) o incluso Vilarinho de Samardã (Vila Real) en Portugal. De las estatuas citadas, la más parecida en cuanto al modo de ejecución es la de Faiões, aunque dicha semejanza haya que matizarla considerablemente. En el caso de Faiões, los rebajes laterales pretenden definir las caderas y los brazos de la estatua y presenta los laterales perfectamente trabajados y uniformizados. En el caso de Castrelo do Val, más que de rebajes, deberíamos hablar de escotaduras, es decir, funcionan como rupturas en el perfil de la pieza. En Faiões encontramos rebajes que mantienen una relación orgánica con la forma de la estatua y que no suponen una ruptura en el perfil de la pieza. El trabajo de Faiões parece obra de un artesano especializado, mientras que Pedra Alta presenta cierto grado de tosquedad.

Una de las circunstancias más señaladas de las estatuas menhir del noroeste es su variedad formal, hasta el punto de que, en algunos casos, el único vínculo entre buena parte de estas estatuas menhir es su distribución geográfica. En este sentido, quisiéramos señalar la existencia de algunas estelas antropomorfas que, posiblemente, no guarden una relación clara con las restantes cuyas características formales están mejor definidas. Por un lado, tenemos una serie de menhires con decoración que pueden representar, de forma muy sumaria, el rostro, elementos de la vestimenta, armas, así como la característica figura rectangular alargada de lados cóncavos. Estas estelas son datadas entre en el Calcolítico y en la Edad del Bronce. Para la mayoría de los investigadores, dichos monumentos serían anteriores a las estelas de guerrero. Así lo plantea Bueno Ramírez (1999) que las sitúa entre el III y II milenios a.C. Ya Almagro Gorbea (1994), data los menhires con cierto perfil antropomorfo, como el de la Serra da Boulhosa o Ermida en el Bronce Antiguo y Medio. Díaz-Guardamino en su tesis doctoral, analizando los objetos representados en diversas estatuas, también defiende una cronología situada entre el 2.200/2.100 y 1.600/1.500 a. C. ${ }^{10}$ (2010). Sin embargo, V. O. Jorge y S. O. Jorge (1990: 201) consideran algunas de las estatuas menhir con perfil antropomorfo y situadas en el valle del Támega como pertenecientes al Bronce Final.

Por otro lado, también suelen ser incluidos en este grupo otros monumentos de cronología no tan clara. Se trata de estelas o menhires sin decoración o con algunos grabados muy simples, que se caracterizan por presentar un perfil aproximadamente antropomorfo, nos referimos a piezas como las de Marco (Vila Pouça de Aguiar-Vila Real) o la de Vilar de Santos (Ourense). En estos dos casos mencionados, no existen argumentos sólidos para situarlos en un momento cronológico concreto. Podríamos argumentar que ambas piedras se sitúan en las inmediaciones de trazados de vías romanas, aunque esta circunstancia también está presen- 
te en otras estatuas con cronología prehistórica como Cruz de Cepos (Montalegre) o Faiões (Chaves), aspecto ya abordado en detalle por Pastor-Fábrega et al. (2011), asimismo, la vinculación a vías romanas también se podría explicar por su posible asociación con líneas de tránsito tradicionales que funcionarían desde la Prehistoria (Ruiz-Gálvez 1998: 177). El entorno arqueológico de una pieza, susceptible de ser trasladada, no siempre constituye un argumento cronológico sólido. Sin embargo, existen evidencias acerca de la utilización de ciertas piedras hincadas en periodos posteriores a época romana. Se conocen estatuas menhir utilizadas como límites territoriales (Almeida y Jorge 1979: 10, Baptista et al. 1995: 147, Alves y Reis 2009: 79, García Sanjuán et al. 2006: 149), lo cual, al igual que en el caso de las vías romanas, tampoco pueden ser utilizadas como argumento para datar con fiabilidad este tipo de artefactos, aunque sí para certificar su utilización en periodos diversos de la historia. Un ejemplo claro de reutilización de piedras hincadas en tiempos históricos lo encontramos en Guizán, entre los términos municipales de Vigo y Mos (Pontevedra), donde un miliario romano fue trabajado en su parte superior y cubierto de numerosas cazoletas, la tradición le atribuye cualidades curativas y fecundadoras (Fig. 9). Quizás un caso semejante pudo ser el de un posible miliario en Monção (Viana do Castelo) que fue alterado del mismo modo que el de Guizán, es decir, mediante una serie de extracciones fue apuntada su parte superior y grabado un rostro humano. Esta piedra sirve de marcador de término a juzgar por las letras insculturadas que presenta. El hecho de que algunas estatuas menhir hayan sido utilizadas en épocas históricas abre la posibilidad de que la producción ex novo de menhires antropomorfos o bien la modificación de estelas prehistóricas pudiera haber tenido lugar en periodos no prehistóricos.

Creemos que existen evidencias para afirmar que, al menos desde el Neolítico y hasta sociedades tradicionales medievales y post-medievales, han sido utilizadas piedras antropomorfas con diversas finalidades, muchas de estas piedras fueron erigidas ex novo $\mathrm{y}$ otras fueron reutilizadas, transformadas y reinterpretadas a lo largo de milenios, por lo que no todos estos monumentos deben tener necesariamente su origen en la Prehistoria y pocos debieron haber funcionado en un solo periodo.
Sobre estos argumentos, y volviendo a Pedra Alta, consideramos como muy probable, la existencia de al menos dos fases en la ejecución del monumento, sin descartar una tercera. Una de estas fases sería la formada por una iconografía semejante a la de una estela de guerrero y una más reciente en la que serían realizadas las escotaduras. La pieza de Castrelo do Val, pudo haber experimentado una transformación en su forma original confiriéndole una forma antropomorfa, lo que implicó la eliminación parcial de algunos grabados, entre los que estaría la punta de la espada y la posible lanza. No podemos concretar en que momento pudo suceder esta alteración, pero no hay razones para descartar cualquiera de los periodos posteriores a la Edad del Bronce. En este sentido, la estela de Castrelo do Val viene a ser un ejemplo más de la reutilización y transformación de este tipo de monumentos a través del tiempo (Jorge y Almeida 1980, Bettencourt 2005, Fábrega-Álvarez et al. 2011).

Si bien existen dudas acerca de la cronología de las escotaduras practicadas en el perfil de la piedra, la presencia de algunos de los grabados, suponen una valiosa fuente de información, puesto que no existen muchas discrepancias acerca de la cronología de las estelas de guerrero que desde hace décadas son datadas en términos generales en el Bronce Final (Almagro Gorbea 1977, Ruiz-Gálvez y Galán Domingo 1991, Galán 2000, Harrison 2004, Díaz, Guardamino 2012,).

El hecho de que la estela de Castrelo do Val presente una iconografía que permite encuadrarla entre las denominadas estelas de guerrero, no nos debe ocultar otro aspecto importante a tener en cuenta y que se relaciona con el estilo y la técnica de grabado empleada. Quizás uno de los características más interesantes es que nos encontramos una iconografía propia del sudoeste ibérico implementada a través de una técnica y estilos más propios del arte rupestre Atlántico. La tradición atlántica se observa en la forma del escudo, que recuerda a las combinaciones circulares de los petroglifos del noroeste. Mientras en las estelas del sudoeste los escudos presentan con frecuencia un perfil irregular y distancias desiguales entre los círculos concéntricos, en Castrelo do Val su forma es perfectamente circular y la distancia entre los anillos es muy regular tal y como es característico en el arte Atlántico. En segundo lugar, en el sudoeste ibérico, los surcos forman parte del cuerpo 

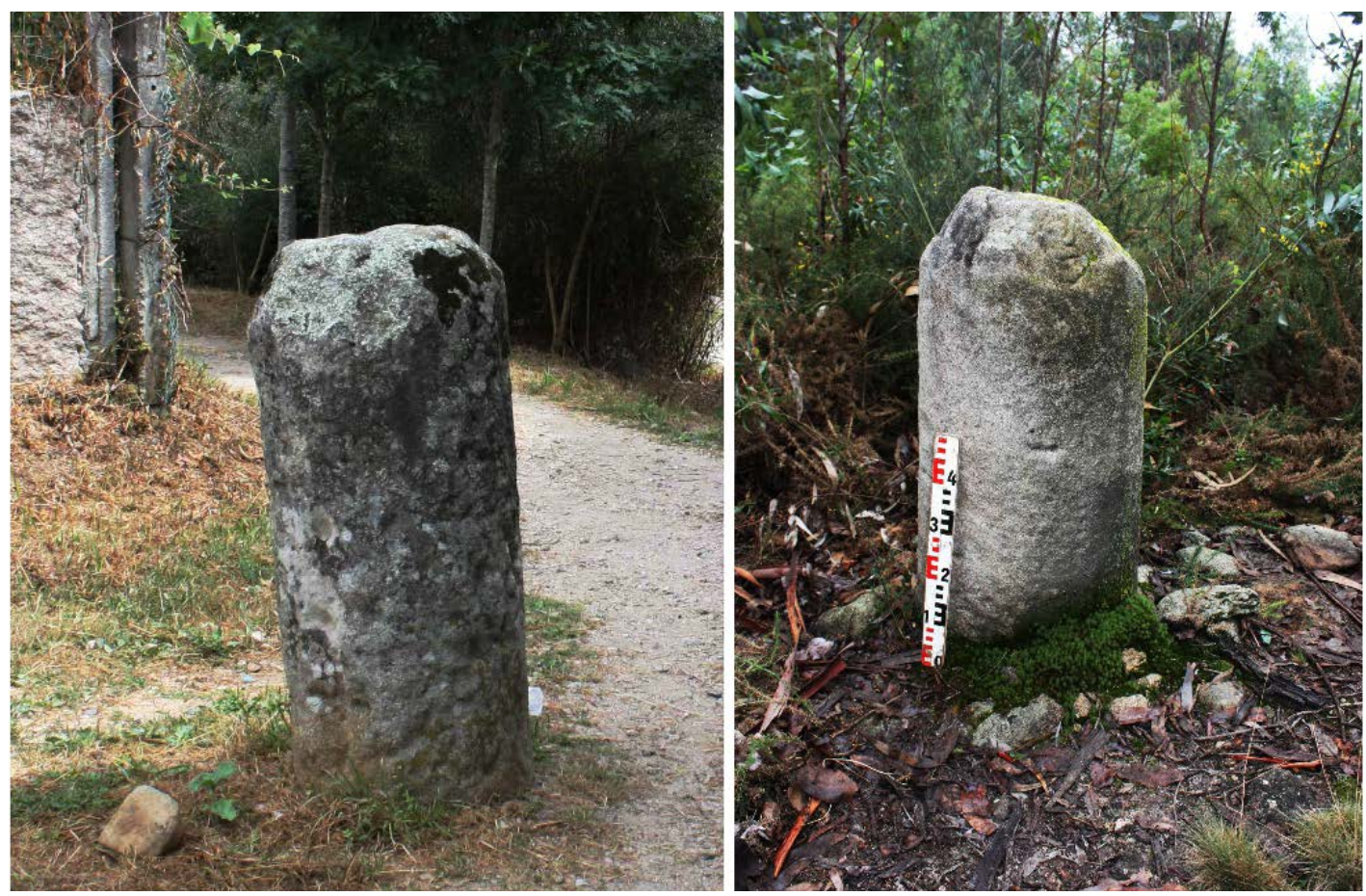

Figura 9. Miliarios convertidos en menhires. Izquierda: miliario de Guizán. Derecha: posible miliario de Monção.

de cada figura, mientras que en la espada y el escudo de la estela orensana los surcos se usan para delimitar la figura, de modo que el espacio comprendido entre los surcos es lo que constituye el objeto representado, por esta razón, el espacio comprendido entre los surcos también está trabajado mediante una leve abrasión con el fin de uniformizarlo tal y como ocurre en el arte Atlántico. Por otro lado, con respecto a la técnica de ejecución de los grabados, encontramos surcos realizados por abrasión, lo que da lugar a surcos suaves y abiertos tan característicos de los petroglifos atlánticos En resumen, podemos constatar que Pedra Alta fue decorada con una iconografía foránea pero ejecutada con una tecnología local, lo que podríamos denominar, siguiendo a Ana Bettencourt (2016: 167), una simbiosis entre dos tradiciones culturales.

\section{Conclusiones}

La presencia de una iconografía propia de las estelas del sudoeste de la Península convierte a Pedra Alta en la representación más septentrional de este tipo. Más al sur han sido localizadas recientemente otras tres en zonas cercanas a Castrelo do Val, nos referimos a la de Tojais en Montalegre (Alves y Reis 2011) y las dos de Monte Forninhos en Castelões (Bettencourt 2013, Silva et al. 2014). La presencia de estos cuatro ejemplares en el noroeste ibérico pudiera estar indicando que, más que una zona apartada del área nuclear de la estelas de guerrero, estemos en la periferia de un territorio arqueológico que se extendería desde el Guadalquivir hasta el Támega.

No podemos conocer en la actualidad el emplazamiento original de la pieza, aunque es muy probable que haya experimentado algún desplazamiento; suponemos que su localización original en el Bronce Final no se encontraría muy lejos del lugar de hallazgo. En relación a esto, debemos tener en cuenta los paralelismos existentes entre el relieve del entorno y el patrón de emplazamiento de las estelas de guerrero. La mayoría de estas estelas, al igual que Pedra Alta, están junto a ríos, cercanos a vados y en lugares de no muy amplia visibilidad (Díaz-Guardamino 2010: 267). Por otro lado, Castrelo do Val se sitúa en una zona de tránsito tradicional, posiblemente relacionada también con el paso de una vía romana, circunstancia apuntada por diversos autores para las estelas del sudoeste (Ruiz-Gálvez y Galán 


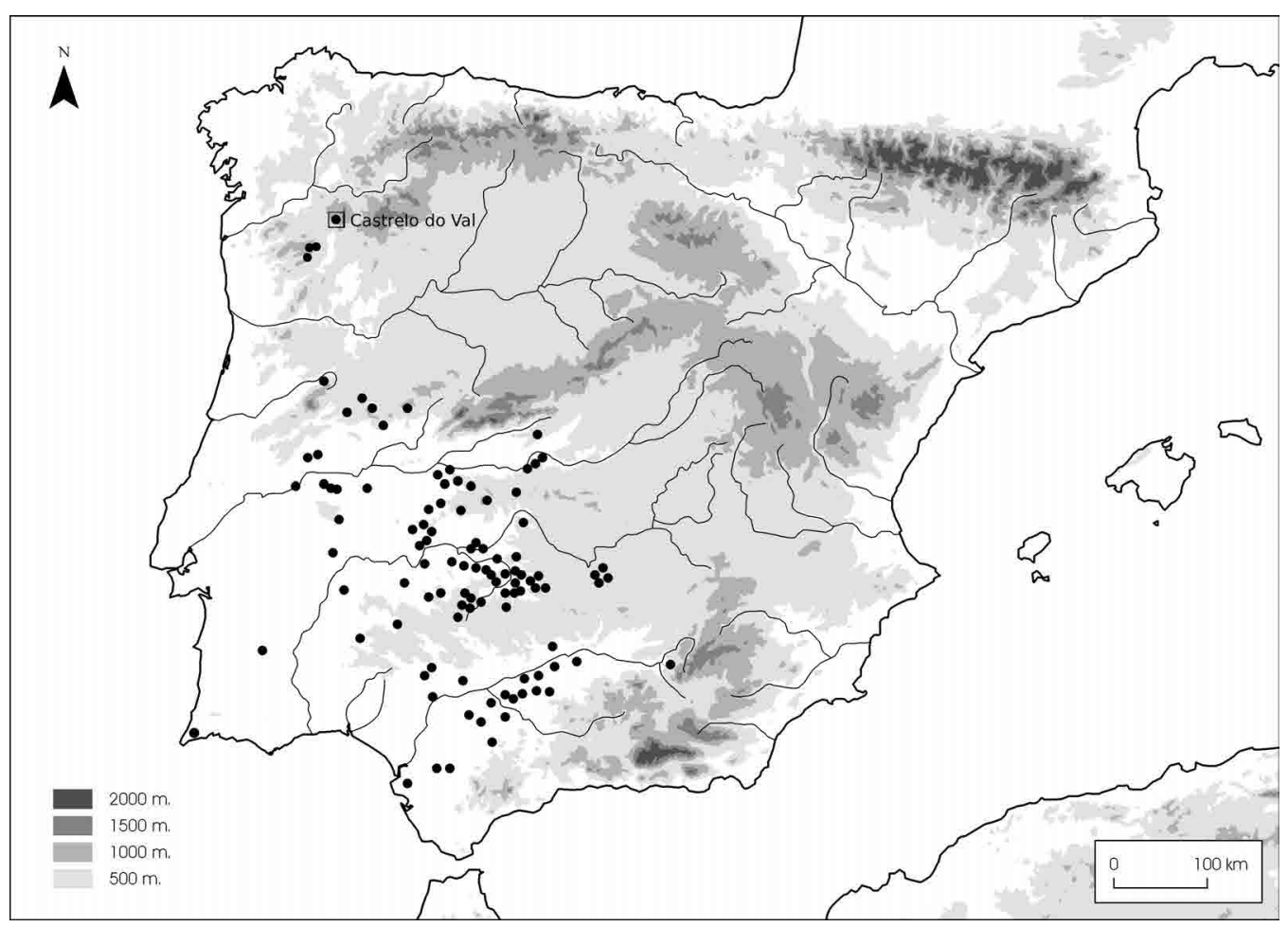

Figura 10. Distribución de las estelas de guerrero.

Domingo 1991, Galán 1993, Celestino 2001). Asimismo, debemos destacar la confluencia en el valle del Támega de numerosas estelas y estatuas menhir y de minería de estaño y oro, circunstancias ambas que bien pudieran estar relacionadas (Bettencourt 2013:167).

En el contexto del noroeste de Iberia, podríamos afirmar que el emplazamiento de la estela difiere considerablemente del patrón de los petroglifos de armas de la Edad del Bronce, que generalmente se sitúan en zonas de monte, en zonas elevadas y alejadas de líneas de tránsito principales (Güimil y Santos 2013). En cambio, se aproxima al de las cistas funerarias del Bronce Inicial generalmente situadas en los valles (Bettencourt 2010).

Respecto a la cronología, el elemento en la iconografía de Castrelo do Val con una datación más clara es sin duda el escudo, se trata de un arma defensiva que, aunque pudo haber tenido antecedentes en el Bronce Medio (Hedges 1991, 1993), su uso se generalizaría en el Bronce Final (1200-800 BC). También podemos contar con la forma de la espada, cuyo enmangue y guarda parecen corresponderse también con espadas de momentos avanzados de la Edad del Bronce. Si a estas circunstancias le sumamos la inequívoca semejanza compositi- va con las estelas de guerrero, consideramos que sería el Bronce Final el periodo en el que habrían sido realizados la mayor parte de los grabados de la estela.

Otros grabados pueden resultar más problemáticos en su adscripción cultural. Resulta particularmente interesante la combinación circular, grabado 7 , que en principio no encajaría en una iconografía típica de estela de guerrero y que aparece cortada en el borde izquierdo de la estela. Dicha destrucción parcial no se explicaría solamente por la práctica de las escotaduras, que no repercuten directamente sobre estos grabados, sino que los círculos parecen haber sido realizados cuando la superficie del soporte era de mayor tamaño, quizás habría que dejar abierta la posibilidad de que se tratase de un diseño realizado en una roca natural y que posteriormente hubiese sido extraída para la construcción de la estela de guerrero, o bien que en origen formase parte de un menhir u ortostato megalítico que experimentó una transformación en sus dimensiones con el fin de producir una pieza más esbelta. En este sentido, debemos recordar las evidentes semejanzas entre la forma del escudo y los círculos concéntricos de los petroglifos atlánticos, algo que no se observa 
en las cercanas estelas de Tojais y Castelões. Quizás no deberíamos descartar la posibilidad de que este diseño formase parte también de un grabado rupestre, al que posteriormente se le practicase la escotadura en $\mathrm{V}$ para darle una forma semejante a un escudo. En definitiva, preferimos dejar abierta la posibilidad de que existiese un primer momento de uso de esta pieza como petroglifo en roca natural encuadrable en la tradición Atlántica datable en el Neolítico (Santos 2012, 2013) y que tiempo después hubiese sido extraída para la elaboración de la estela. Posteriormente, cuando la estela pierde su significado original, en un periodo indeterminado, es transformada en una escultura antropomorfa practicando cuatro escotaduras que afectaron a parte de los grabados.
La pieza de Castrelo do Val, constituye una evidencia más de los contactos entre las diversas comunidades de la Península Ibérica a lo largo de la Prehistoria Reciente. También supone un argumento más que ilustra el destacado papel de los ítems de prestigio, como son las armas y objetos suntuarios en los contactos a larga distancia entre las élites de comunidades distantes en la Edad del Bronce. Dichos intercambios no solo involucrarían bienes materiales, sino también iconografías e imágenes asociadas a la construcción ideológica de dichas élites. En el caso que nos ocupa, el artesano o artesanos que realizaron los grabados emularon la iconografía de las estelas de guerrero llevando a cabo su obra siguiendo una tecnología y un estilo local observable en el arte rupestre del noroeste.

\section{Agradecimientos}

Quisiéramos agradecer la colaboración de la profesora Beatriz Comendador y al proyecto Alto Támega y a Raquel López por la revisión del texto.

\section{Notas}

6. El Museo Provincial de Ourense ha publicado un informe sobre la pieza en su página web: http://www. musarqourense.xunta.es/peza mes/a-pedra-alta-de-castrelo-do-val/

7. La información arqueológica utilizada en este artículo procede de dos proyectos. Uno de ellos es la catalogación realizada por Amado Rolán, cuyos resultados constan en el informe titulado Inventario y Catalogación de Yacimientos Arqueológicos del Ayuntamiento de Castrelo do Val. Ourense; DEPOSITADO en la Consellería de Cultura e Xuventude. Xunta de Galicia en 1991. El otro es Proxecto Alto Támega: Accións na Paisaxe Patrimonial de 2013, realizado por B. Comendador Rey y F. González Insua del GAAT de la Universidade de Vigo.

8. Este trabajo en concreto fue financiado por el Instituto de Ciencias del Patrimonio, Consejo Superior de Investigaciones Científicas.

9. B. Comendador Rey y F. González Ínsua en "Proxecto Alto Támega: Accións na Paisaxe Patrimonial", p. 9.

10. Díaz-Guardamino Uribe 2010. Las estelas decoradas en la Prehistoria de la Península Ibérica. Tesis doctoral leída en Universidad Complutense.

\section{Bibliografía}

Almagro Gorbea, M. (1977): El Bronce Final y el periodo Orientalizante en Extremadura.Instituto Español de Prehistoria. Consejo Superior de Investigaciones Científicas. Madrid.

Almagro Gorbea, M. (1994): Las estelas antropomorfas en la Península Ibérica. Tipología, dispersión, cronología y significado. En La statuaria antropomorfa in Europa del Neolítico atta la Romanizazzione. Actas del Congresso de La Spezia-Pontremoli. 1988: 69-108.

Almeida, C.A.F.; Jorge, V.O. (1979): “A estátua-menir de Faioes (Chaves)". Trabalhos do Grupo de Estudos Arqueológicos do Porto, 2: 1-24.

Alves, L. B.; Reis, M. (2011): Memorias de pedra, símbolos de identidade. Duas novas peças escultóricas de Cervos (Montalegre, Vila Real). En R. Vilaça (Coord.) Estelas e estátuas-menires: da Pré à Protohistória. Actas das IV Jornadas Raianas (Sabugal 2009). 187-216. 
Aparicio Casado, B.; Carrera Ramírez, F.; Peña Santos, A. (2013). Arte rupestre en Galicia. Ed. Cumio. Pontevedra.

Baptista, A.M. (1995): A estátua-menir feminina da Ermida. A Idade do Bronze em Portugal. Discursos de poder. Ed. S.O. Jorge, Lisboa, Museu Nacional de Arqueología: 27-28.

Bettencourt, A. M. S. (2005): La estatuaria: las estatuas-menhires. En J. M. Hidalgo Cuñarro (coor. y dir.) Arte y Cultura de Galicia y Norte de Portugal. Arqueología. Tomo I: 170-178. Nova Galicia Edicións, Vigo.

Bettencourt, A. M. S. (2010): "La Edad del Bronce en el noroeste de la península Ibérica". Trabajos de Prehistoria 67. $\mathrm{n}^{\circ}$ 1.: 139-173. Instituto de Historia - CSIC.

Bettencourt, A. M. S. (2013): "O Bronce Final no Noroeste português. Uma rede complexa de memórias, lugares e açôes." Estudos Arqueológicos de Oeiras 20: 157-172. Oeiras, Câmara Municipal de Oeiras.

Bueno Ramírez, P. (1991): Estatuas menhir y estelas antropomorfas en la Península Ibérica. La situación cultural de los ejemplares salmantinos. En Del Paleolítico a la Historia: 81-97. Salamanca. Museo de Salamanca.

Celestino Pérez, S. (2001): Estelas de guerrero y estelas diademadas. La precolonización y formación del mundo tartésico. Ed. Bellaterra. Barcelona.

Collado Giraldo, H. (2015): "New Representations of "Chariots" in the Rock Art of Extremadura and Some Considerations of the Archaeological Context". Arts 4: 49-60. MDPI AG.

Díaz-Guardamino, M. (2010): Las estelas decoradas en la prehistoria de la Península Ibérica. Ed. Universidad Complutense de Madrid. Madrid.

Díaz-Guardamino, M. (2012): "Estelas decoradas del Bronce Final en la Península Ibérica:datos para su articulación cronológica". Anejos del Archivo Español de Arqueología, LXII. Instituto de Historia. CSIC.

Fábrega-Álvarez, P.; Fonte, J.; González García, F. J. (2011): "Las sendas de la memoria. Sentido, espacio y reutilización de las estatuas-menhir en el noroeste de la Península Ibérica". Trabajos de Prehistoria, 68, $\mathrm{n}^{\mathrm{0}}$ 2: 313-330. Instituto de Historia. CSIC.

Galán Domingo, E. (1993): Estelas, paisaje y territorio en el bronce final del suroeste de la Península Ibérica. Ed. Universidad Complutense de Madrid. Madrid.

Galán Domingo, E. (2000): Las estelas del Suroeste entre el Atlántico y el Mediterráneo. Actas del IV Congreso Internacional de Estudios Fenicios y Púnicos. Vol. IV: 1789-1797. 2 al 6 de Octubre de 1995. Cádiz. Universidad de Cádiz.

García Sanjuán, L.; Wheatley, D. W.; Fábrega Álvarez, P.; Hernández Arnedo, M. J.; Polvorinos del Río, A. (2006): "Las estelas de guerrero de Almadén de la Plata (Sevilla). Morfología, Teconogía y Contexto". Trabajos de Prehistoria, 63 - 2: 135-152. Instituto de Historia, CSIC.

Güimil-Fariña, A.; Santos-Estévez, M. (2013): "Territorialidad en la Edad del Bronce del noroeste de la Península Ibérica". Revista d'Arqueologia de Ponent, 23: 9-26. Universitat de Lleida.

Harrison, R.J. (2004): Symbols and Warriors. Images of the European Bronze Age. Western Academics \& Specialist Press Ltd. Bristol.

Hedges, R.E.M.; Housley, R.A.; Bronk, C.R.; Van Klinken, G.J. (1991): "Radiocarbon dates from the oxford ams system: archaeometry datelist 12." Archaeometry, 33(1): 121-134.

Hedges, R.E.M.; Housley, R.A.; Bronk, C.R.; Van Klinken, G.J. (1993): "Radiocarbon dates from the oxford ams system: archaeometry datelist 17". Archaeometry, 35(2): 305-326.

Caninas J., Henriques, F., Baptista, A., Pires, H. (2011): "Pedra das Cruzinhas. Notícia de um monólito gravado na fronteira entre os concelhos do Sabugal e Guarda". Sabucale 3:33-54.

Jorge, V. O.; Almeida, C. A. F. de (1980): "A Estatua-menir fálica de Chaves". Trabalhos do Grupo de Estudos Arqueológicos do Porto 6: 5-24.

Jorge, V.O.; Jorge, S.O. (1990): "Statues-menhirs et stèles du nord du Portugal". Revista da Faculdade de Letras, II Serie, 7: 299-324.

Pires, H.; Gonçalves Seco, L., Fonte J.; Correia Santos, M. J.; Sousa, O. (2014): "Morphological Residual Model: A Tool for Enhancing Epigraphic Readings of Highly Erosioned Surfaces". Information Technologies for Epigraphy and Cultural Heritage. Studi Humanisti - Serie Antichista, Sapienza Universitá Editrice: 133-144.

Ruiz-Gálvez Priego, M. (1998): La Europa Atlántica en la Edad del Bronce. Un Viaje a las Raíces de la Europa Occidental. Ed. Crítica. Madrid.

Ruiz-Gálvez Priego, M.; Galán Domingo, E. (1991): Las Estelas del Suroeste como Hitos de Vías Ganaderas y Rutas Comerciales. Trabajos de Prehistoria 48: 257-273. Instituto de Historia, CSIC.

Santos-Estévez, M. (2012): Atlantic Rock Art: transformation and tradition during Late Prehistory. En The Prehistory of Iberia: Debating Early Social Estratification and the State: 231-248. Ed. María Cruz Berrocal Leonardo García Sanjuán y Antonio Gilman. Routledge.

Santos-Estévez, M. (2013): Una propuesta de periodización para el arte rupestre atlántico. Petroglifos, 
paleoambiente y paisaje. Estudios interdisciplinares del arte rupestre de Campo Lameiro. TAPA. 42, pp. 283 - 289. INCIPIT-CSIC.

Seoane Veiga, Y. (2009): Propuesta metodológica para el registro del arte rupestre de Galicia. Cuadernos de Arqueoloxía e Patrimonio, CAPA 23. LaPA-CSIC. Santiago de Compostela.

Terroba Souto, Y. 2015: La estatuaria de la Edad del Bronce en el noroeste ibérico. Fol de Veleno 5: 201234. SAGA.

Silva, A.C.F.; Parente, J.R.; Lobato, M.J.F.; Jorge, R. (2014): As estelas de Castelões e as representações proto-históricas do poder. In Arqueologia em Portugal 150 anos: 625-632. Lisboa: Associação dos Arqueólogos Portugueses (1863-2013). 